LA-UR-

\title{
TITLE: LOS ALAMOS ADVANCED FREE-ELECTRON LASER
}

AUTHOR(S): K. C. D. Chan, R. H. Kraus, J. Ledford, K. L. Meier, R. E. Meyer, D. Nguyen, R. L. Sheffield, F. L. Sigler, L. M. Young, T. S. Wang, W. L. Wilson, and R. L. Wood

\section{SUBNiITTED TO: Thirteenth International Free-Electron Laser Conference Santa Fe, NM August 25-30, 1991}

\section{DISCLAIMER}

\begin{abstract}
This report was prepared as an account of work sponsored by an agency of the United States This report was prepared as an account of work sponsored by an agency thereof, nor any of their employees, makes any warranty, express or implied, or assumes any legal liability or responsibility for the accuracy, completeness, or usefulness of any information, apparatus, product, or process disclosed, or represents that its use would not infringe privately owned rights. Reference herein to any specific commercial product, process, or service by trade name, trademark, manufacturer, or otherwise does not necessarily constitute or imply its endorsement, recommanufacturer, or otherwise does not necessarily constitute or imply its endorserentere the views and opinions of authors expressed herein do not necessarily state or reflect those of the United States Government or any agency thereof.
\end{abstract}

By acceptance of this article, the publisher recognizes that the U.S. Government retains a nonexclusive, royalty-free license to publish or reproduce the published form of this contribution, or to allow others to do so, for U.S. Government purposes.

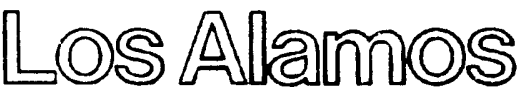




\title{
LOS ALAMOS ADVANCED FREE-ELEC ${ }_{\perp}$ RON LASER*
}

K. C. I. Chan, R. H. Kraus, J. Ledford, K. L. Meier,

R. E. Meyer, D. Nguyen, R. L. Sheffield, F. L. Sigler,

L. M. Young, T. S. Wang, W. L. Wilson, and R. L. Wood

Los Alamos National Laboratory

MS H825, Los Alamos, NM 87545

U. S. A.

\begin{abstract}
At Los Alamos, we are building a free-electron laser (FEL) for industrial, medical, and research applications. This FEL, which will incorporate many of the new technologies developed over the last decade, will be compact in size, robust, and user-friendly.

Electrons produced by a photocathode will be accelerated to $20 \mathrm{MeV}$ by a highbrightness accelerator and transported using permanent-magnet quadrupoles and ilipoles. They will form an electron beam with an excellent instantaneous beam quality of $10 \pi \mathrm{mm}$ mrad in transverse emittance and $0.3 \%$ in energy spread at a peak current up to to $300 \mathrm{~A}$. Including operation at higher harmonics, the laser wavelength extends from $3.7 \mu \mathrm{m}$ to 0.4 $\mu \mathrm{m}$.
\end{abstract}

In this paper, we will describe the project and the progress to date.

\section{Introduction}

The Advanced Free-Electron Laser (AFEL) project is a five-year program funded internally by the Los Alamos National Laboratory. The mission of the project is to advance the state of the art of Free-Electrnn Laser (FEL) with a goal to build FELs useful for industrial, medical, and research applications. The requirements for such FELs are low cost, compactness, robustness, high reliability, and user-friendliness.

* Work supported by Los Alamos National Laboratory Institutional Supporting Research, under the auspices of the United States Department of Energy. 
Presently, we are building a FEL to fulfill these requirements using state-of-the-art components currently available. The operational experience of such a FEL will help us to identify the researches required for future improvements in the areas including electron source, wiggler, optical system, diagnostics, and control system. We will push the frontiers of these areas in the following years.

Figure 1 shows a floor plan of the AFEL Facility [1]. The total floor area is approximately $40 \mathrm{ft}$ by $70 \mathrm{ft}$. The main areas are the Control Room, the Laser Room, and the Vault. The Control Room contains the computer-based control system and the signalprocessing equipments. The Laser Room contains the drive-laser for the photo-electron source and the equipments to analyze the FEL light. The FEL system is installed in the Vault.

Figure 2 shows the layout of the FEL system. The electron-beam parameters are summarized in Table 1. The system consists of five major subsystems: a photo-electron source, a high-brightness linac, an emittance-preserving beamline, a micro-wiggler FEL o:cillator, and a computer-based control system. These subsystems are described in the follo:ving sections.

\section{Photo-electron Source}

A photo-electron source [2] is necessary to achieve the compactness and high beam brightness of the system. It has two major components: a drive laser and a photocathode.

Figure 3 shows a schematic of the drive laser. The modelocked Nd:YLF oscillator generates 60-ps long micropulses at a rate of $108 \mathrm{MHz}$. These micropulses are compressed in length to $10 \mathrm{ps}$ and amplified. They are then frequency doubled to $523 \mathrm{~nm}$. The output laser power, averaged over an $1-\mu \mathrm{s}$ macropulse, is $1 \mathrm{~kW}$.

The photocathode has a $\mathrm{CsK}_{2} \mathrm{Sb}$ surface. A container with six photocathodes, called the 6-pack configuration, will be installed. The cathodes will have quantum efficiencies of $5 \%$ or better. In fact, with the available drive-laser power, the quantum efficiency required will be $<0.2 \%$. With the 6-pack configuration and high drive-laser power, the effective lifetime of the photo-electron snurce will be longer than a week. 
High Brightness Accelerator

Figure 4 shows a schematic of the accelerator. A copper structure is installed inside a vacuum vessel. The structure is an on-axis coupled structure operating at $1300 \mathrm{MHz}$. It is $1.2 \mathrm{~m}$ long consisting of one half accelerating cell followed by 10 full accelerating cells. The photocathode is installed at the half accelerating cell. The structure is thermally isolated to the vacuum vessel so that it can operate at nitrogen temperature with reduced power loss.

The structure has been designed to produce a $20-\mathrm{MeV}$ beam with high brightness. Simulations showed that the instantaneous transverse emittance (normalized and 90\%) of better than $10 \pi \mathrm{mm}$ mrad and the energy spread of better than $0.3 \%$ is possible. Special considerations [3] have been taken to achieve these beam qualities. First, the first two and half accelerating cells are coupled using a four-coupling-slots scheme, so that the asymmetric focusing force due to coupling slots is minimized. Second, the structure is detuned to have a field of $5 \mathrm{MV} / \mathrm{m}$ in the first coupler cell, so that conditions for multipactoring do not exist. Third, the first two and half cells have a shape slightly different from the rest of the accelerating cells, so that the threshold current for regenerative beam breakup is raised above $1 \mathrm{~A}$. Fourth, a high field gradient of $25 \mathrm{MV} / \mathrm{m}$ is used in the first half accelerating cell, so that electrons can be quickly accelerated and the effects of space-charge force is minimized.

\section{Emittance-preserving Beamline}

The beamline, as shown in Fig. 5, has been designed to preserve the good beam qualities from the linac [4]. It is simple and short. The entire beamline is installed on a $6 \mathrm{ft}$ $x 10 \mathrm{ft}$, vertically-mounted optical table. The electron beam from the linac is matched to the rest of the beamline with two quadrupole doublets. Such a matching section simplifies the operation of the system because the beam dynamics for the rest of the system is separated from the beam dynamics in the accelerator. The beam is then bent by $60^{\circ}$ with an achromatic bend consisting of two dipoles and one quadrupole. It traverses a microwiggler and is bent further by a spectrometer towards a beam dump below ground. 
The alignment requirements of the components along the beamline for preserving the beam quality were described in Ref. [5]. In order to minimize wakefield effects, beampipes of 1" diameters are used throughout the beamline (except at the wiggler) and the electron beam is tightly focused, particularly at the achromatic bend.

Diagnostics observing Optical Transition Radiations will be used to measure beam positions and emittances [6]. A system of beam position monitors and beam steerers will be installed to provide active beam-position control [7].

We use only permanent-magnet dipoles (Fig. 6) and quadrupoles (Fig. 7) along the beamline. Permanent-magnet transport elements [8] are used because they are compact in size, simple in operation, and have practically no power and cooling requirements. They are also expected to produce magnetic fields without jitters. The fields in these devices will be varied with stepper motors. They can be varied linearly in a range between $-10 \mathrm{~T} / \mathrm{m}$ and $60 \mathrm{~T} / \mathrm{m}$ for the quadrupoles and between 0.1 and $0.5 \mathrm{~T}$ for the dipoles.

\section{Micro-wiggler FEL Oscillator}

The oscillator is $1.4 \mathrm{~m}$ long with $1^{\mathrm{n}}$ mirrors. Either broadband silver mirrors or narrow band multilayered dielectric mirrors will be used. During initial operation, a 1-cm period permanent-magnet wiggler (Fig.8) operating at the fundamental will be used to produce $3.7 \mu \mathrm{m}$ light. With 24 periods, an efficiency of $2.5 \%$ is expected. Later on, an electromagnetic wiggler with $0.3-\mathrm{cm}$ period and 40 periods will be used. When operating at the fifth harmonics, it will generate light at $0.36 \mu \mathrm{m}$.

\section{Computer-based Control System}

A computer-based control system has the advantages of minimized staffing requirement, flexibility in reconfiguration, piecemeal implementation, and easy and integrated data access. The control system for AFEL [9] is developed using the Experimental Physics and Industrial Control System (EPICS) [10] developed at the Los Alamos National Laboratory. The EPICS provides distributed processing within a high performance run time environment, and includes a comprehensive set of applications 
development tools. These tools save us considerable time and effort in building the run time database, operator displays, and sequence programs.

Figure 9 shows the hardware environment of the control system. VME crates and SUN Workstations communicate via the Ethernet. The VME crates is the basic input/output controller. It contain an Allan/Bradley scanner to control the input/output of digital and analog signals, an IEEE 488 Card to control various commercial equipments, and a stepper-motor Controller to control the stepper motors. Figure 10 shows the software environment including the development tools. The screen display is designed using the Display Manager and Display Language. The database is constructed and modified with the Database Configuration Tool. Sequence programs used to control processes is written using the State Notation Language.

\section{Progress to date}

The construction of the facility is close to completion. The major components have been designed and are in various stages of fabrication. The linac structure has been tuned and assembled. It will be installed in the vacuum vessel and is scheduled for rf-power operation in November. The fabrication of the dipoles and quadrupoles will be completed early in 1992. Electron beam and FEL experiment will be expected in the spring of 1992.

\section{Reference}

1. K. Meier, "Engineering Considerations of the Advanced Free Electron Laser Facility," this proceedings.

2. R. L. Sheffield, "Progress in Photoinjectors for Linacs," Proceedings of the $\mathbf{1 9 9 0}$ Linear Accelerator Conference, September 10-14, 1990, Albuquerque, New Mexico, Los Alamos National Laboratory Report LA-12004-C Conference, pp. 269-272, March 1991.

3. R. L. Sheffield, J. Browman, B. E. Carlsten, and L. M. Young, "Physics Design of the High Brightness Linac for the Advanced Free-Electron Laser Initiative at Los Alamos,", this proceedings.

4. T. F. Wang, K. C. D. Chan, R. L. Sheffield, and W. L. Wilson, "Design of the Ebeam Transport Line for the AFEL," this proceeding. 
5. S. Hartman, A. Lombardi, R. Sheffield, and T. Wang, "electron Benm Sensitivity Study of the Los Alamos Advanced Free-Electron Laser Beam Line," this proceedings.

6. R. B. Feldman, A. H. Lumpkin, D. W. Rule, and R. B. Fiorito, "Developments in On-line Electron Beam Emittance Measurements Using Optical Transition Radiation Technique," Proceedings of the 11th International Free Electron Laser Conference, Naples, Florida, Aug. 28-Sept. 1, 1989, edited by L. R. Elias and I. Kimel, published by Elsevier Science Publishers, North-Holland, The Netherlands, pp. 193-198.

7. R. E. Shafer, "Characteristics of Directional Coupler Beam Position Monitors," IEEE Trans. Nucl. Science NS-32, pp 1933 (1985).

8. K. Halbach, "Conceptual Design of a Permanent Quadrupole Magnet with Adjustable Strength," Nucl. Inst. Meth. 206 pp. 353-354 (1983).

9. W. L. Wilson, M. W. May, and A. J. Kozubal, "Rapid Development of a Measurement and a Control System for the Advanced Free-Electron Laser," this proceedings.

10. A. J. Kozubal, L. R. Dalesio, J. O. Hill, and D. M. Kerstiens, "Run Time Environment and Applications Tools for the Ground Test Accelerator Control System," Accelerator and Large Experimental Physics Control Systems, D. P. Gurd and M. Crowley-Milling, Eds. (ICALEPCS, Vancouver, British Columbia, Canada, 1989), pp. 288-291. 
Table 1

AFEL, beam parameters

charge per micropulse shape of micropulse

micropulse length

peak micropulse current

micropulse frequency

average macropulse current

output energy

macropulse length

macropulse rate

macropulse beam power

instantaneous energy spread

instantaneous emittance

micropulse energy spread

micropulse emittance

duty factor

$\begin{array}{rl}2.6(4.6)^{\mathrm{a}} & \mathrm{nC} \\ \text { gaussian (square) } & \\ 11.7(15.4) & \mathrm{ps} \\ 220(310) & \mathrm{A} \\ 108 & \mathrm{MHz} \\ 0.28(0.50) & \mathrm{A} \\ 20.1 & \mathrm{MeV} \\ 10(50) & \mu \mathrm{s} \\ 10(20) & \mathrm{Hz} \\ 5.6(10.0) & \mathrm{MW} \\ <0.1 & \% \\ <10 & \pi \mathrm{mm} \mathrm{mrad} \\ <0.3 & \% \\ 32(20) & \pi \mathrm{mm} \mathrm{mrad} \\ 10^{-4}\left(10^{-3}\right) & \end{array}$

a All numbers in brackets are parameters for accelerator operation at liquid-nitrogen temperature. 


\section{Figure Captions}

1. Floor plan of the AFEL Facility

2. The FEL system of AFEL

3 Schematics of the AFEL drive laser

4. A schematics of the AFEL high brightness accelerator

5. A schematics of the emittance-preserving beamline

6. A schematics of the permanent-magnet dipole

7. A schematics of the permanent-magnet quadrupole doublets

8. A schematics of the permanent-magnet micro-wiggler

9. A schematics of the hardware environment of the AFEL Control System

10. A schmetics of the software environment of the AFEL Control System 


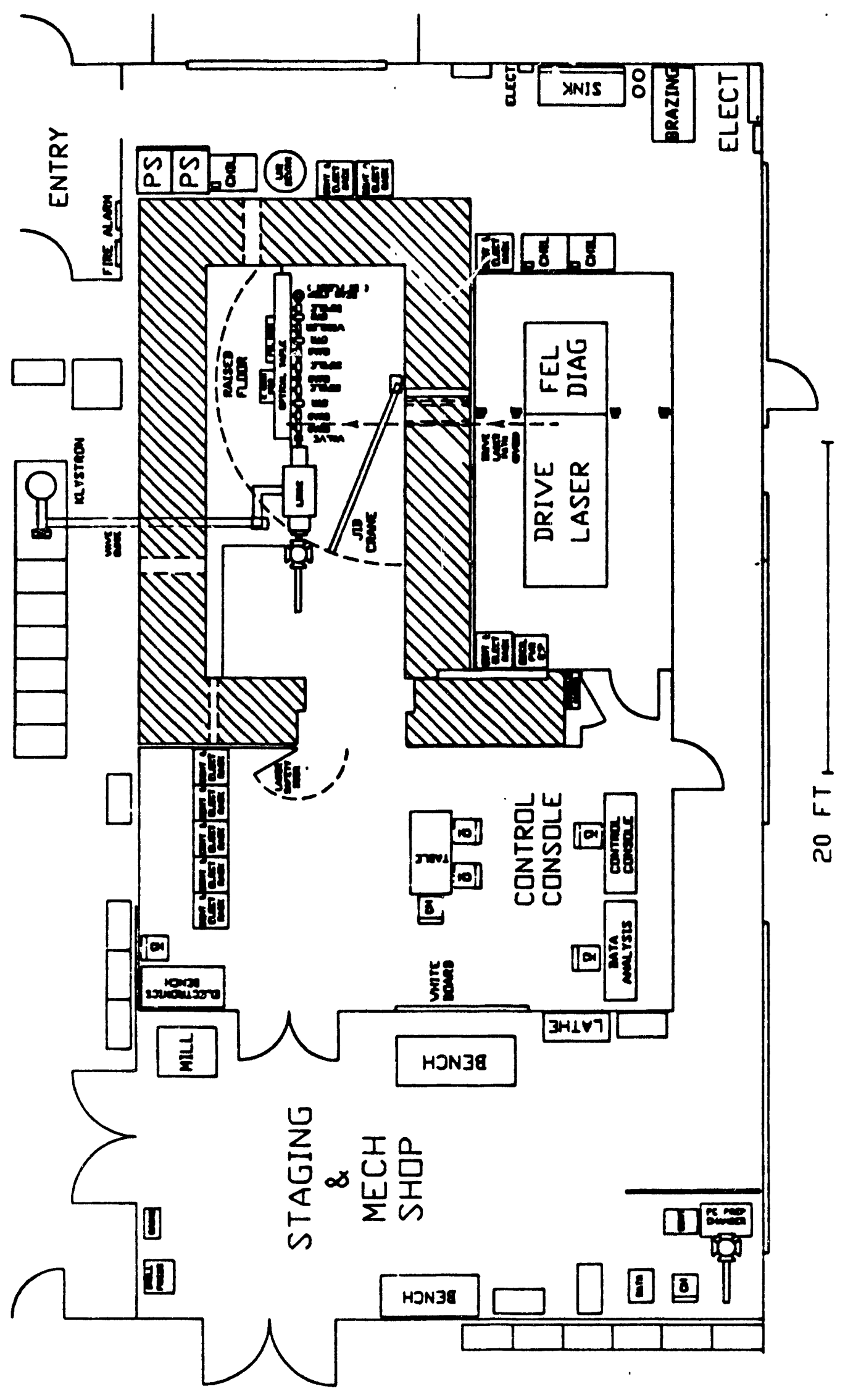




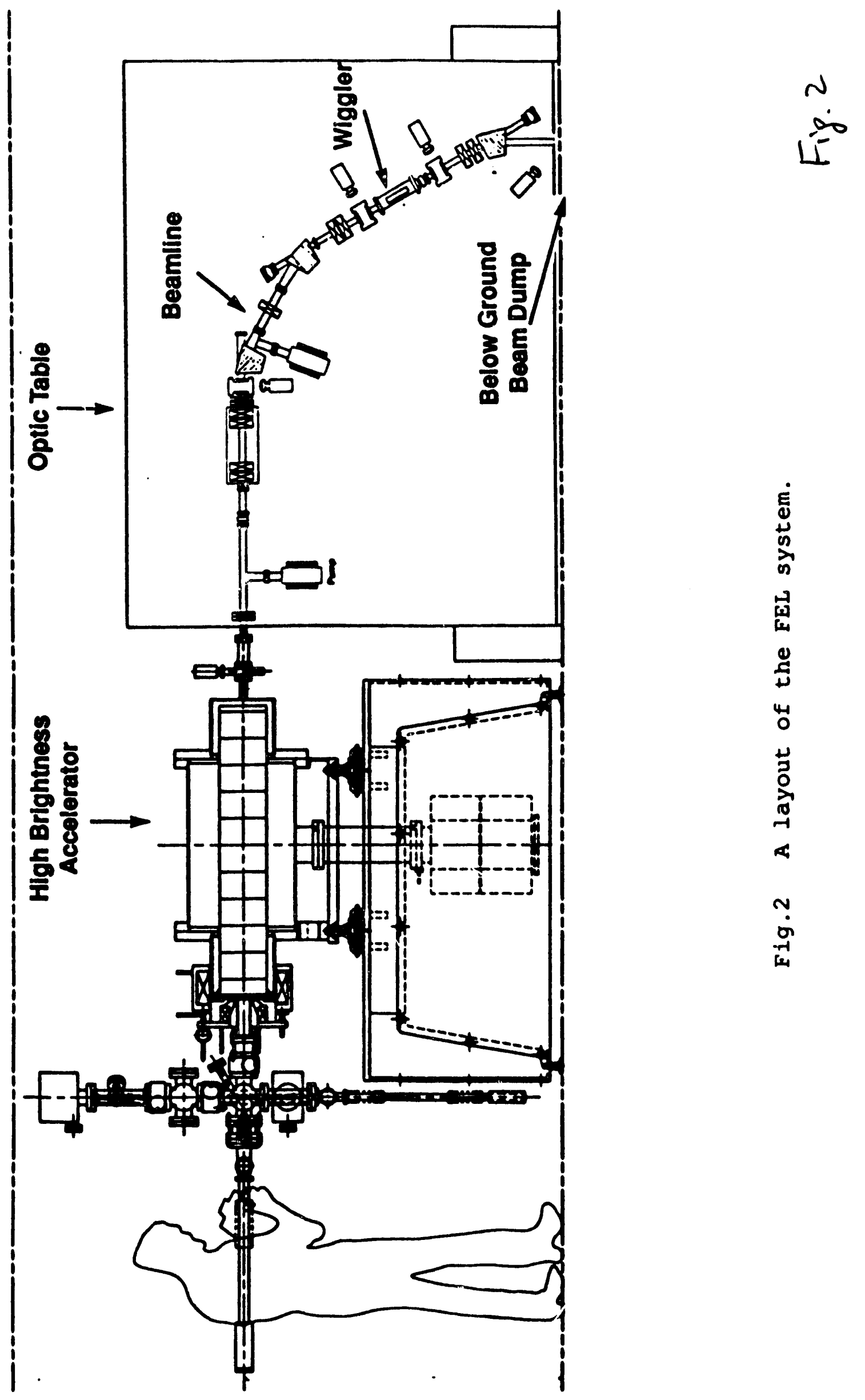




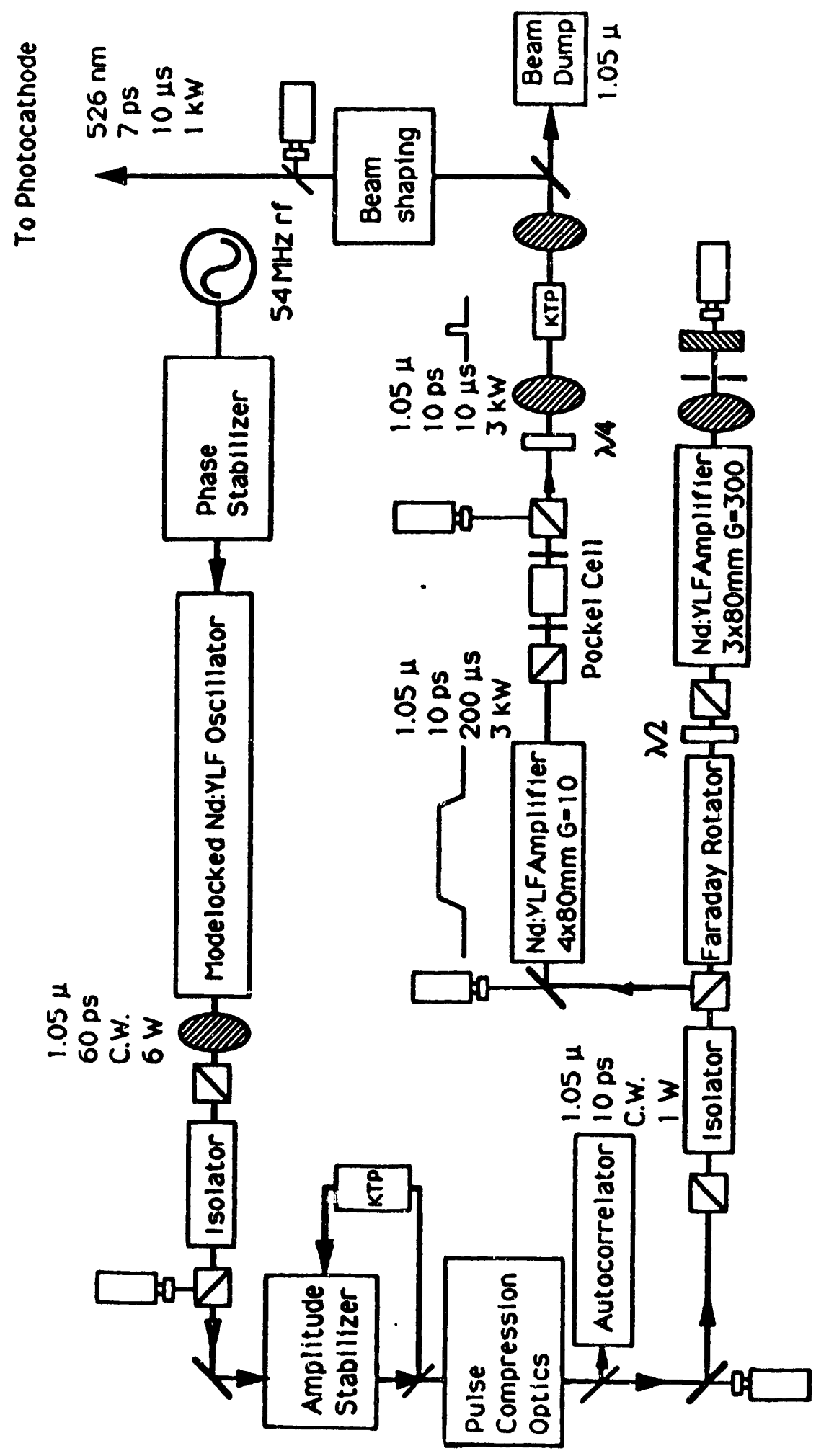

$\frac{a}{i j}$ 


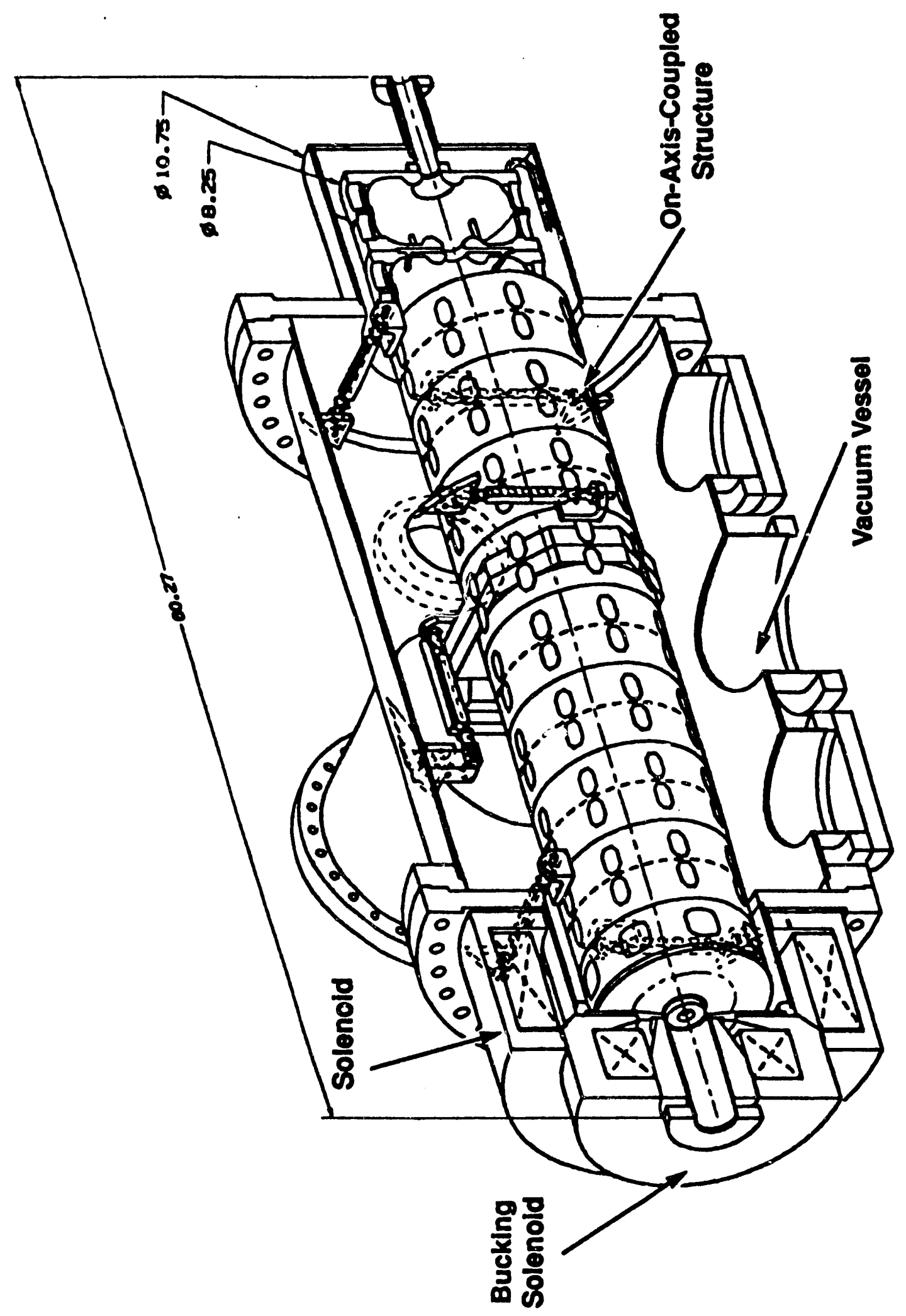




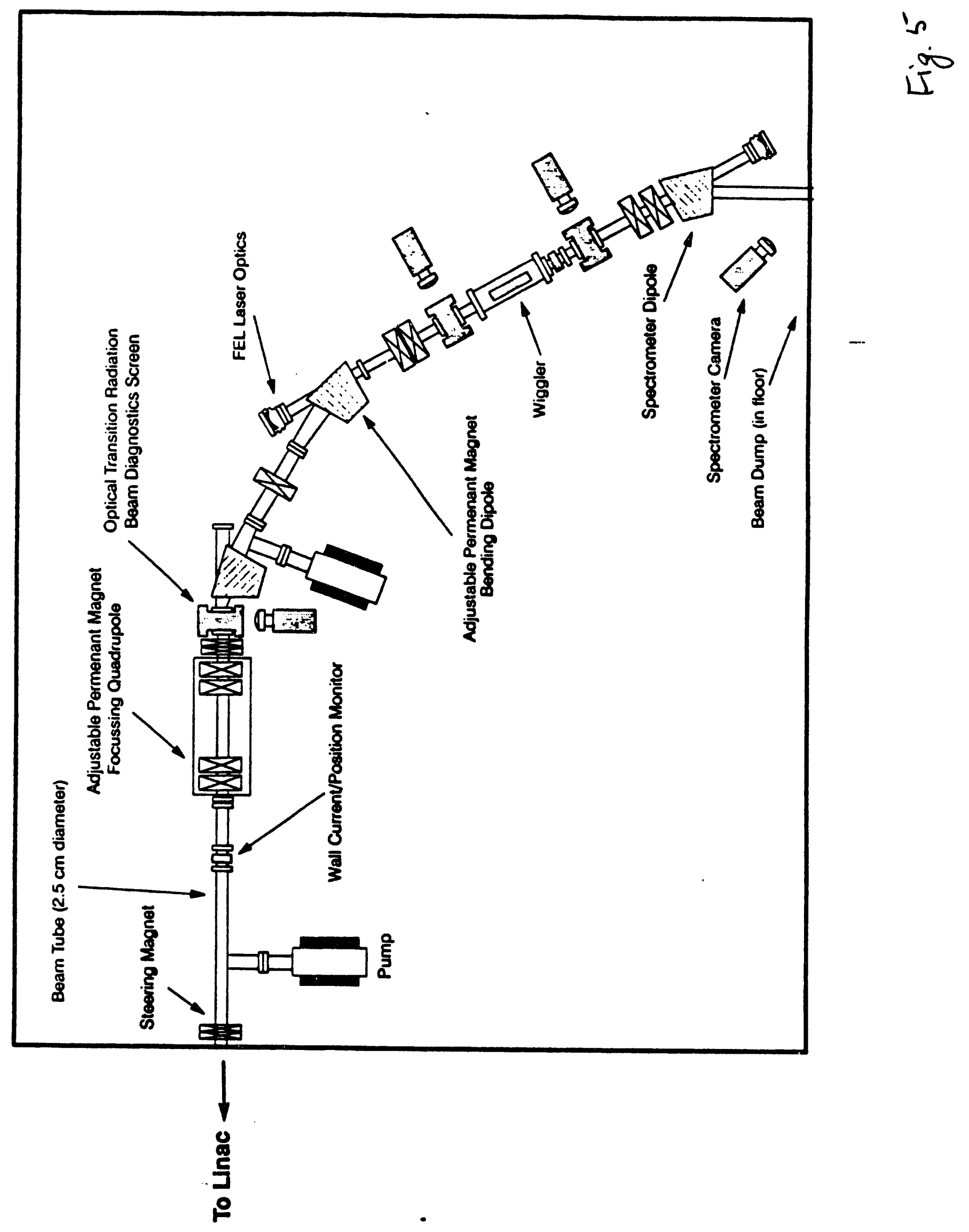




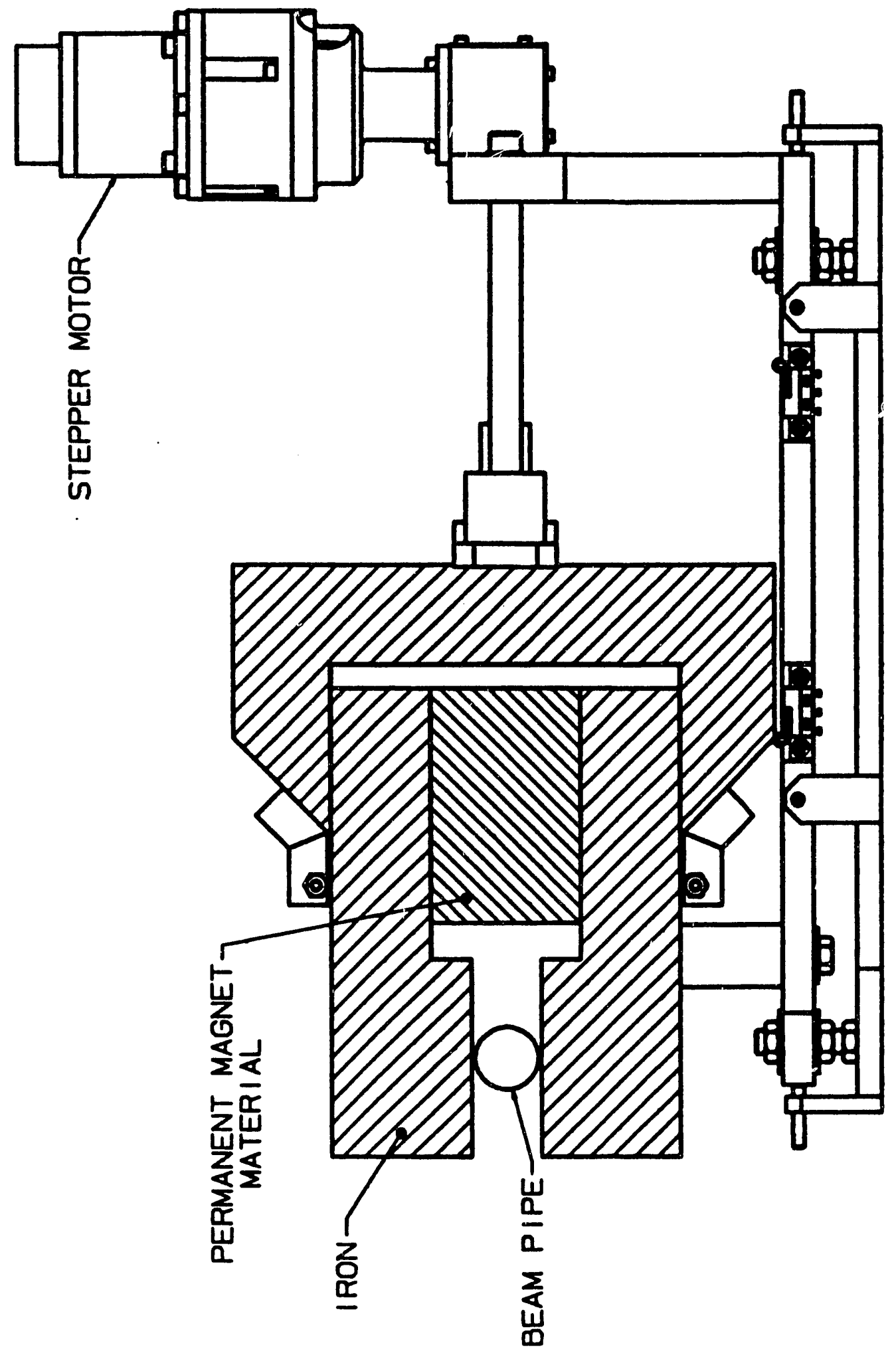



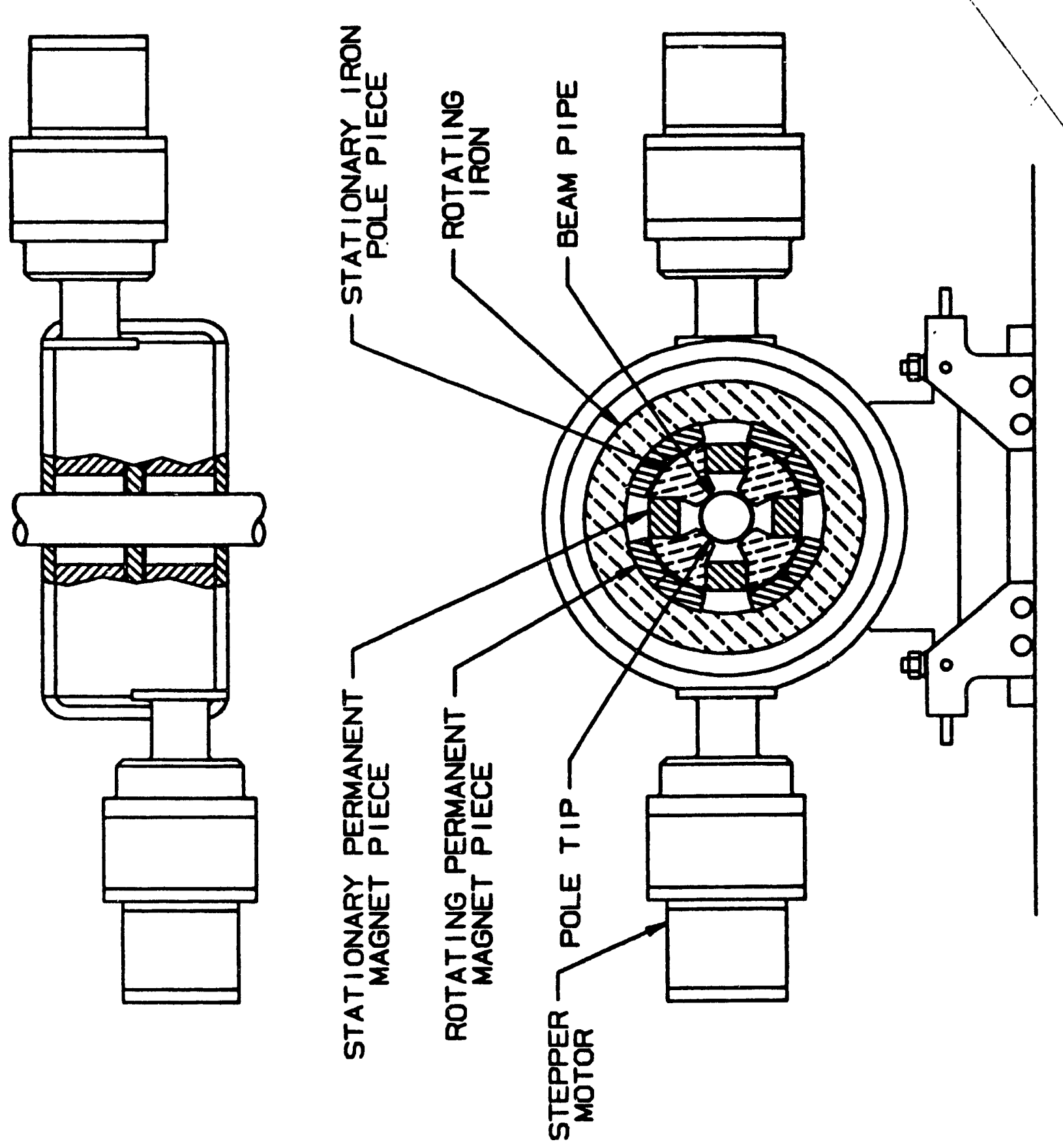


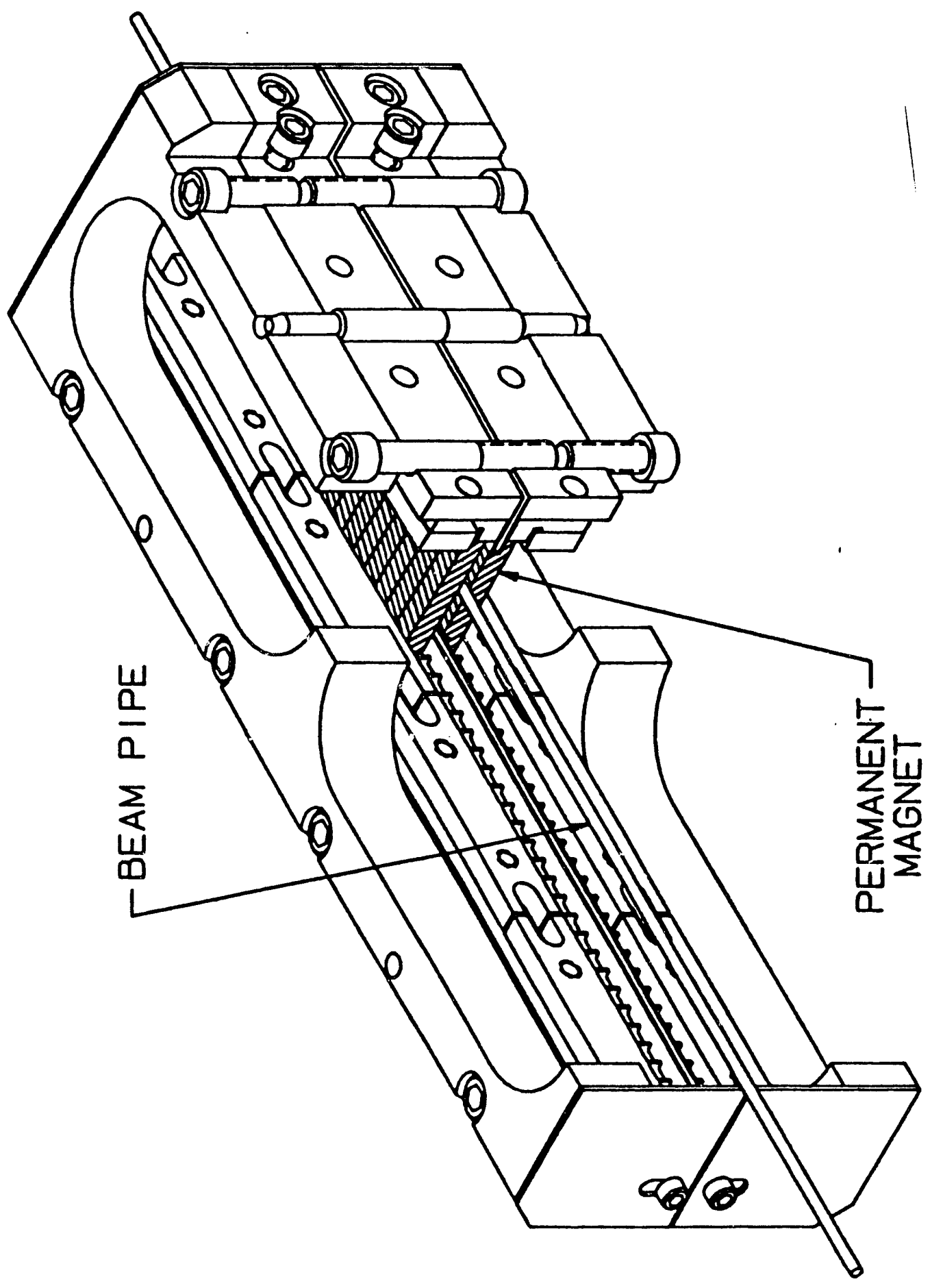




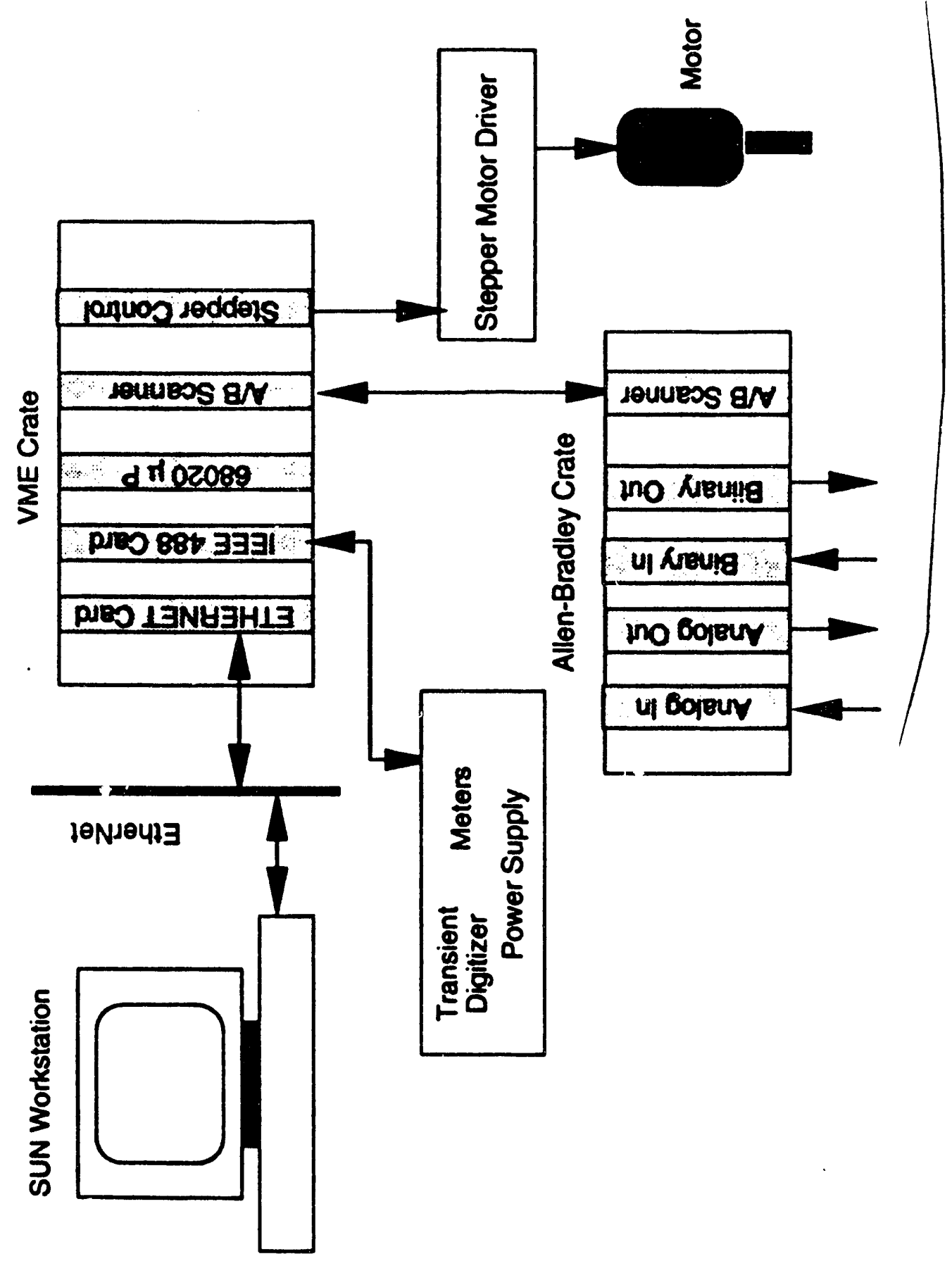




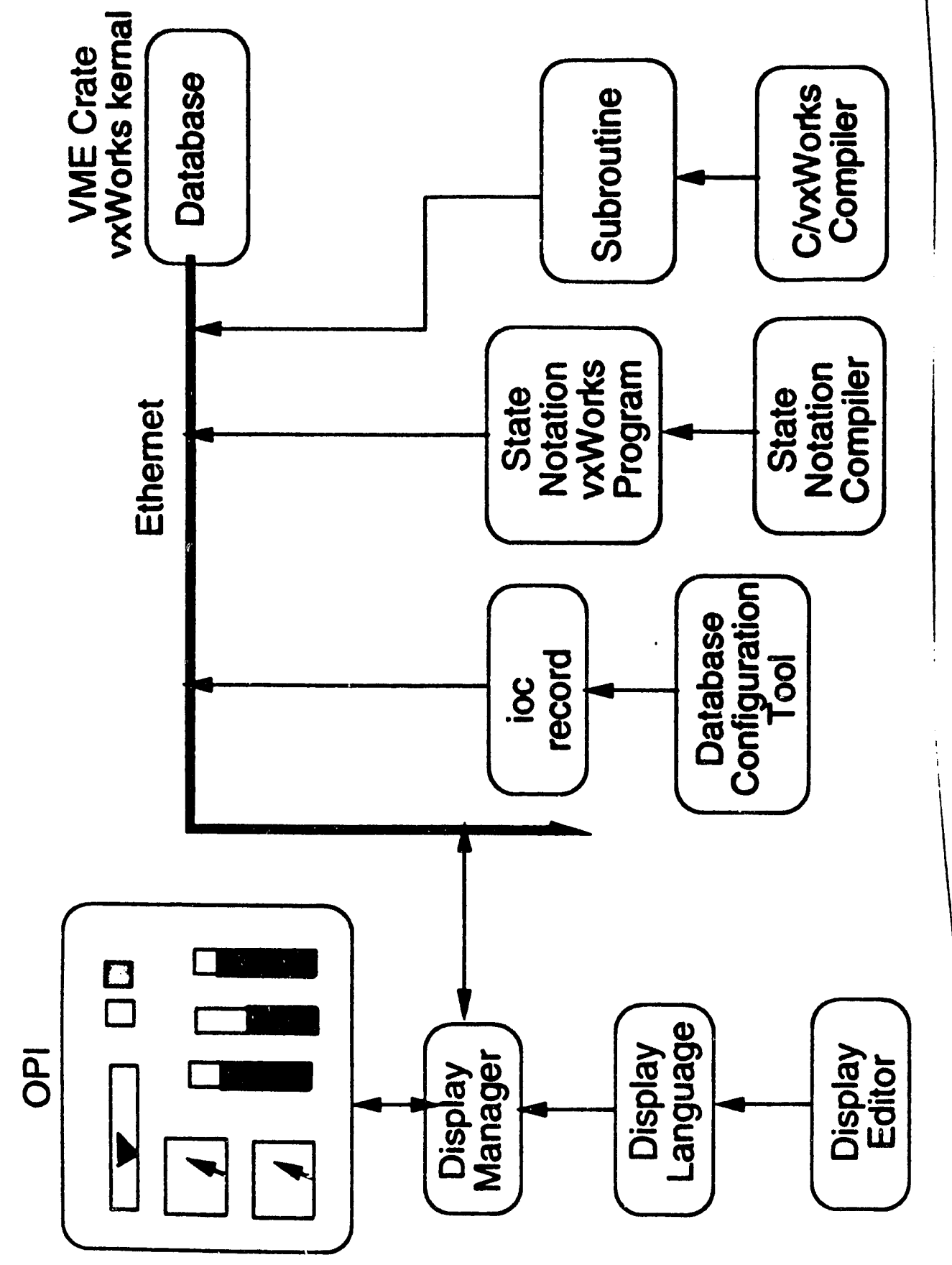

인

का 

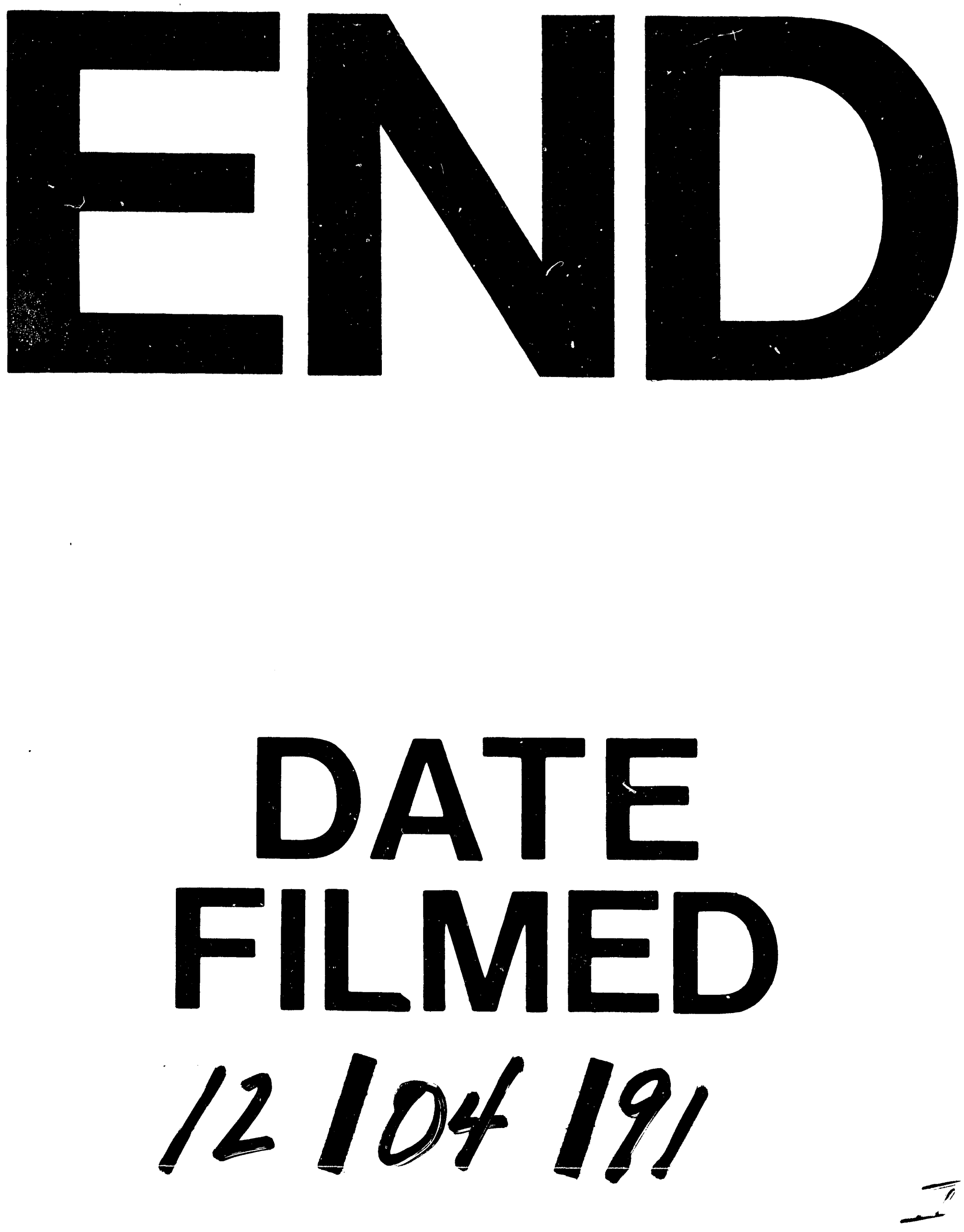

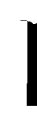




$$
\text { ' ' }
$$

